\title{
Conception of eco-friendly cement based on natural pozzolan to improve rheological behavior of concrete
}

\author{
Mansour Sabria Malika*, Ghernouti Youcef \\ Research Unit: Materials, Process and Environment, Civil Engineering department, University M'Hamed \\ Bougara of Boumerdes, Algeria \\ * Corresponding Author: s.mansour@univ-boumerdes.dz
}

Received: 27-06-2020

Accepted: 31-08-2020

\begin{abstract}
The pozzolan of Beni- Saf region (North-West Algeria) is a natural material of volcanic origin with the ability to react with cement hydration products and improve its properties. Therefore, its use in the production of new cementitious materials will protect the environment. It will therefore be interesting to exploit this source as a partial cement substitution. In this work, a rheometric investigation was carried out to assess the performance of the natural pozzolan substituted to cement at variable rates ranging from $5 \%, 10 \%, 15 \%$ to $20 \%$ in order to obtain an ecological concrete. As the rheological behavior of concrete depends on the behavior of the cement paste, the effect of pozzolan on the latter was analyzed using static flow tests and dynamic creep and oscillation tests. The results of the rheometric tests have shown that in flow, the pozzolan improves the fluidity and in oscillation mode, it generates a viscous behavior of the cementitious pastes compared to elastic behavior of the control paste. Furthermore, the transient study (creep / recovery) made it possible to highlight the liquid viscoelastic character of the cement pastes. With $10 \%$ of pozzolan, the rheological behavior of the paste is viscous liquid which seems to be the best. The use of pozzolan as cement substitution has significant environmental, economic and technical advantages, namely the development of natural pozzolan, reduction of $\mathrm{CO}_{2}$ emissions during the manufacture of cement as well as energy reduction and finally improvement of the properties of fresh concrete.
\end{abstract}

Key words: Rheology; Flow; Creep; Oscillation; Cement; Pozzolan.

\section{Introduction}

The rheological behavior of cement paste and fresh concrete is a subject of considerable interest. Fresh concrete is a fluid material and its rheological behavior affects the way it is treated, therefore the measurement and control of rheological parameters is very important in the production of quality concrete. Much research (Ferraris et al., 2001; Park et al., 2005) has been carried out in order to improve the rheological and mechanical properties by using fine particles or mineral additions which can contribute to the improvement of workability in the fresh state, the microstructure densification of the cement matrix and the development of high mechanical properties due to their hydraulic or pozzolanic properties on the scale of concrete (Tattersall \& Banfill, 1983). Natural pozzolans have been used as a cementitious material for thousands of years. It is often used in concrete as a partial replacement for cement (Lam et al.; 2018). The use of natural pozzolan and industrial by products in concrete as a partial replacement for cement has economic, environmental benefits by decreasing the gases emitted during cement production and technique by increasing the durability of concrete at later ages (Sarker \& McKenzie, 2009; Lam et al., 2017). Belaribi et al., (2003) studied Influence of the Beni-saf pozzolan on the mechanical characteristics of concrete. They have shown that substituting cement by $20 \%$ of pozzolan cement gives the concrete mechanical performances that equals, and surpasses those of the control concrete in the long term. Khelifa et al. (2008) have shown that the pozzolan rock from Beni-Saf has pozzolanic properties. Thus, it is used and marketed mainly to cement factories which use it as an active addition at rates of 15 to $20 \%$ in the manufacture of 
composite cements (Kaid et al., 2009). Moreover, research has been undertaken on the durability of mortars based on this pozzolan kept in aggressive environments (Ghrici et al., 2006; Ghrici et al., 2007). They found a gain in the compressive strengths of mortars stored in a $5 \%$ solution of sodium sulfates with the use of $20 \%$ and $30 \%$ pozzolan in the medium term (6 months). Also, the study of the permeability to chlorine ions of concretes based on this natural pozzolan was limited to the measurement of the electric charge passing through the concrete sample. This result revealed a better permeability of concrete based on $30 \%$ pozzolan compared to that of a control concrete and a ternary concrete based on $20 \%$ natural pozzolan and $10 \%$ limestone filler. In addition Siad (2010) studied the effect of this natural material on the mechanical properties and on the resistance in aggressive environments of mortars and concretes, either in substitution of part of the cement or in addition to concrete.

In this work, the fines of the pozzolan powder are used as cement substitution. This substitution has advantages, both ecological by the reduction of greenhouse gases during the manufacture of cement and economic by reducing the manufacture of cement. The aim of this work is to seek the best replacement rate of natural pozzolan powder which generates the best rheological behavior of cement paste which reflects the behavior of concrete. For this, the effect of pozzolan (substituted to cement at 5\%,10\%,15\% and 20\%) on the rheological behavior of cement pastes was analyzed. This analysis was carried out under imposed stress thanks to the AR2000 rheometer by flow tests in static mode and creep and oscillation tests in dynamic mode. The rheological parameters (shear stress, viscosity, and compliance, mechanical properties such as storage and loss modulus) were evaluated.

\section{Materials and Methods}

\subsection{Materials}

CEMI 52.5 cement conforming to European standard NF EN 197-1 (2001) was preferably used because it contains a large amount of clinker (at least $95 \%$ by weight), has a high reactivity at an early age, and guarantees 28-days a minimum compressive strength of $52.5 \mathrm{MPa}$ on mortars standardized according to standard NF EN 196-1 (2006). As a cement substitution, pozzolan powder was used. This pozzolan is a material of volcanic origin extracted from the Ghar Ben Brikhou deposit located $30 \mathrm{~km}$ south-east of the Beni Saf cement plant (north-west of Algeria). It is a material with an ability to react with lime in the presence of water, and to form compounds with binding properties. This pozzolan is supplied in the form of crushed pumice and slag type rocks. The pozzolan was selected, homogenized, dried, crushed and reduced to powder using a micro-grinder (Figure 1).

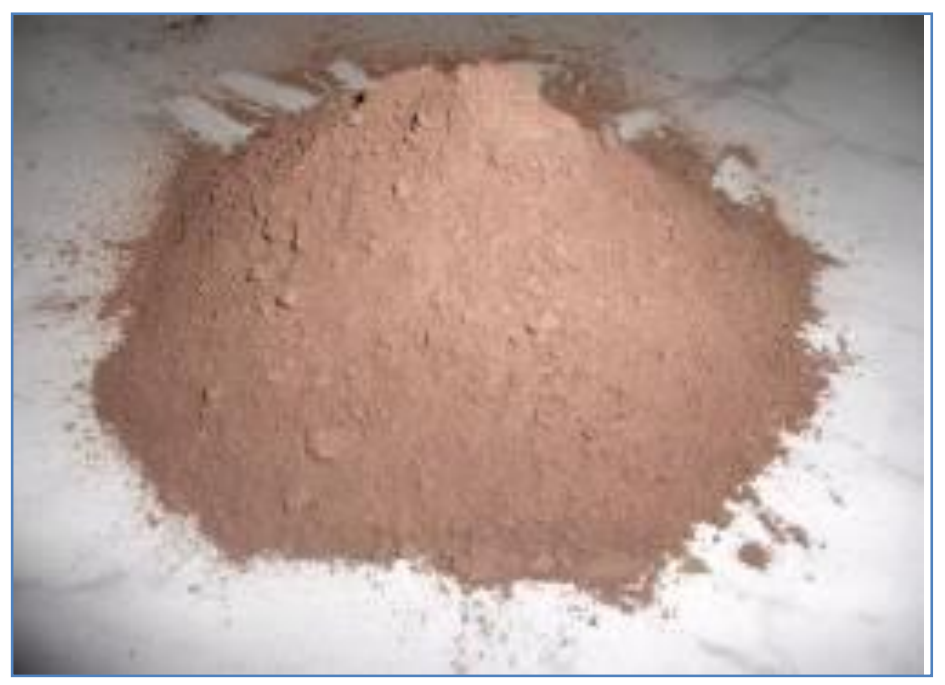

Fig 1. Pozzolan powder 


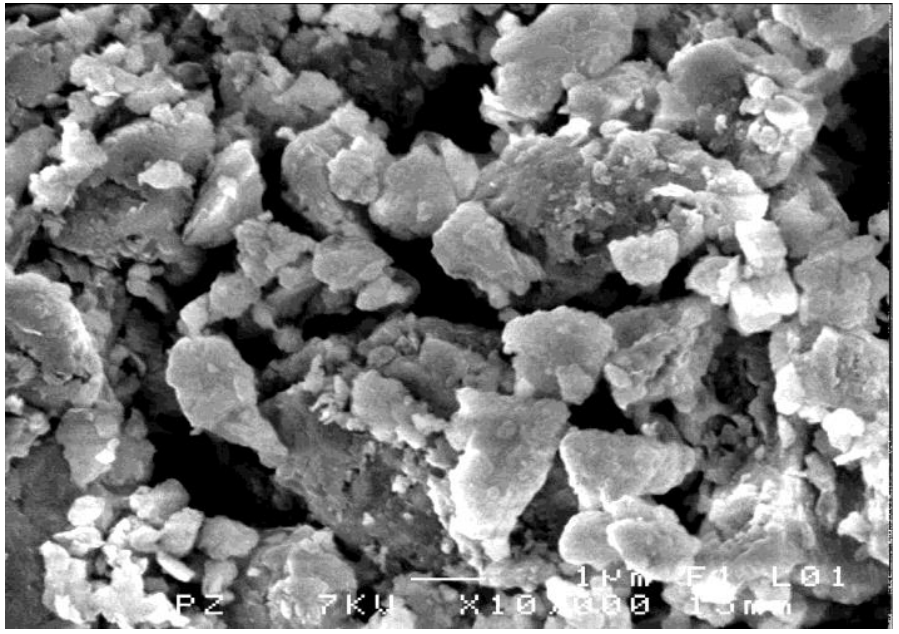

Fig 2. Morphology of the Pozzolan (SEM, secondary electron mode)

The morphological appearance of the pozzolan powder is shown in Figure 2. The physical properties and the chemical composition of the cement and the pozzolan are given in Table 1, Table 2 and 3. The chemical analysis showed that the pozzolan contains a high percentage of silica, an average rate of Aluminum, and a low rate of calcite and iron. On the other hand, the other minerals (Mg, K, N) are in small percentage. High water-reducing superplasticizer based on modified polycarboxylate phosphonate and deionized water for preparing the cement blended were used.

The X-ray diffraction diagram (Figure 3 ) shows that the crystalline mineral phases of the pozzolan are cordierite $\mathrm{Al}_{3} \mathrm{Mg}_{2} \mathrm{AlSiO}_{5} \mathrm{O}_{18}$ in large quantity, the analcime $\mathrm{NaAlSiO}_{6} \cdot \mathrm{H}_{2} \mathrm{O}$ in average quantity, very little cristobalite $\mathrm{SiO}_{2}$ and hematite as well as traces of illite $\left(\mathrm{K}, \mathrm{H}_{3} \mathrm{O}\right)$ $(\mathrm{Al}, \mathrm{Mg}, \mathrm{Fe})_{2}(\mathrm{Si}, \mathrm{Al})_{4} \mathrm{O}_{10}\left[(\mathrm{OH})_{2},\left(\mathrm{H}_{2} \mathrm{O}\right)\right]$.

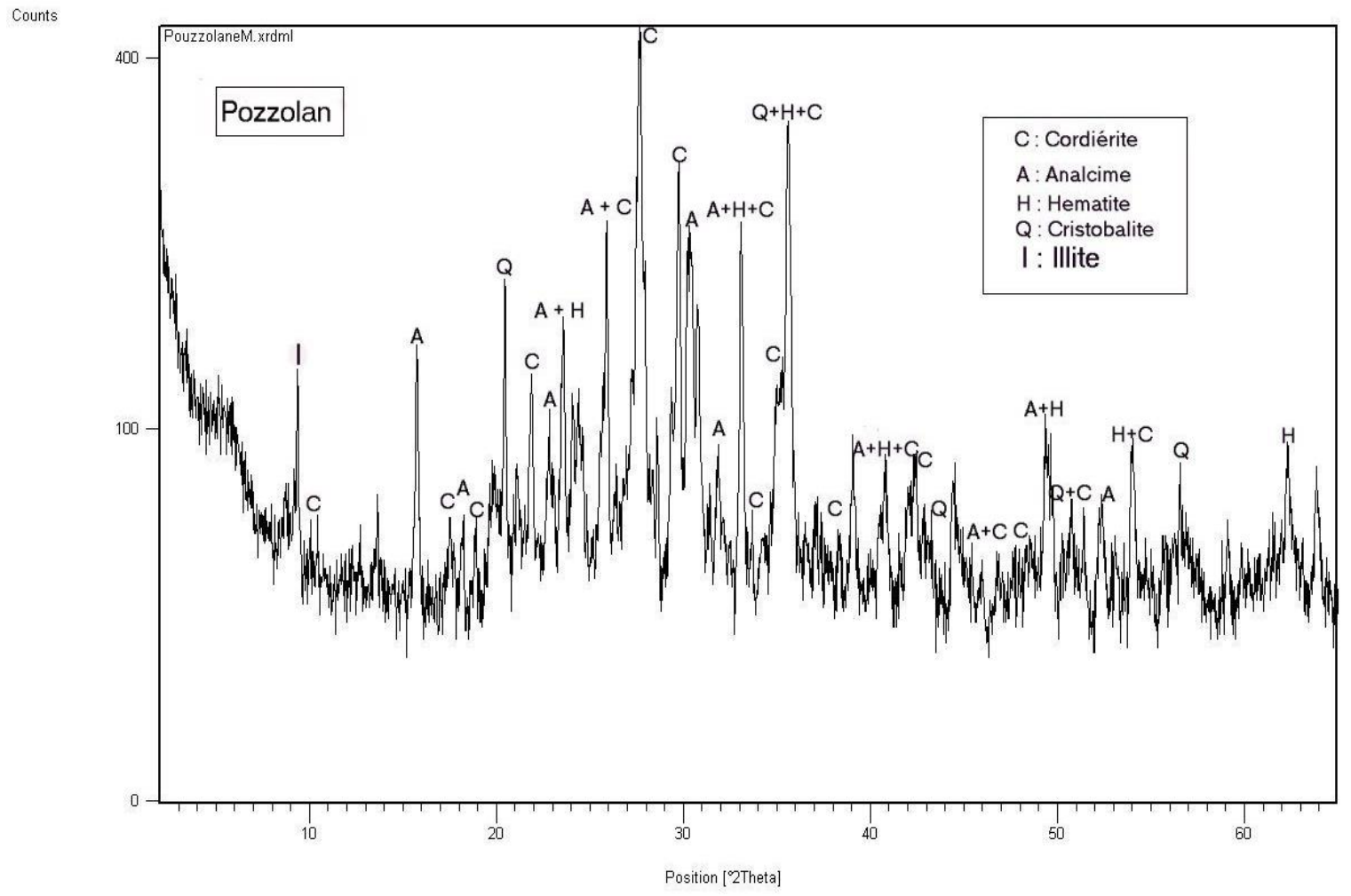

Fig 3. X-ray diffraction diagram of the pozzolan ( $\mathrm{Cu} k \alpha$ radiation $\mathrm{Ni}$ filter) 
Table 1. Physical properties of cement CEMI 52.5 and pozzolan

\begin{tabular}{|l|l|l|}
\hline Materials & Cement & PZ \\
\hline Blaine specific surface $\left(\mathrm{cm}^{2} / \mathrm{g}\right)$ & 4200 & 6200 \\
\hline Specific gravity $\left(\mathrm{g} / \mathrm{cm}^{3}\right)$ & 3.15 & 2.79 \\
\hline Mineral activity $\mathrm{mg} \mathrm{Ca}(\mathrm{OH}) / \mathrm{g}$ & - & 149.8 \\
\hline Water demand $(\%)$ & 27.4 & 27.6 \\
\hline
\end{tabular}

Table 2. Chemical composition of cement CEMI 52.5 and pozzolan.

\begin{tabular}{|c|c|c|c|c|c|c|c|c|c|c|}
\hline Oxides \% & $\mathrm{SiO}_{2}$ & $\mathrm{Al}_{2} \mathrm{O}_{3}$ & $\mathrm{Fe}_{2} \mathrm{O}_{3}$ & $\mathrm{CaO}$ & $\mathrm{MgO}$ & $\mathrm{SO}_{3}$ & $\mathrm{~K}_{2} \mathrm{O}$ & $\mathrm{Na}_{2} \mathrm{O}$ & $\mathrm{PF}^{2}$ & $\mathrm{CL}^{-}$ \\
\hline \hline Cement & 19.85 & 4.80 & 2.75 & 63.60 & 1.45 & 3.45 & 0.90 & 0.15 & 2.20 & 0.002 \\
\hline Pozzolan & 44.78 & 16.53 & 9.01 & 10.97 & 4.59 & 0.17 & 1.15 & 3.42 & 6.55 & 0.014 \\
\hline
\end{tabular}

Table 3. Mineralogical composition of cement CEMI 52.5 (\%).

\begin{tabular}{|c|c|c|c|c|}
\hline $\mathrm{C}_{3} \mathrm{~S}$ & $\mathrm{C}_{2} \mathrm{~S}$ & $\mathrm{C}_{3} \mathrm{~A}$ & $\mathrm{C}_{4} \mathrm{AF}$ & Gypsum \\
\hline \hline 62.0 & 10.2 & 8.1 & 8.4 & 5.0 \\
\hline
\end{tabular}

\subsection{Preparation of cement pastes}

Cement blended containing replacement rate of 5\%,10\%, 15\% and $20 \%$ of natural pozzolan have been developed. All the mixtures were prepared under the same conditions with $\mathrm{W} / \mathrm{C}$ of less than 0.30 and $2 \%$ of superplasticizer.

\subsection{Testing samples}

The rheological measurements were carried out using AR2000 rheometer with imposed stress. The samples are kept at a temperature of $20^{\circ} \mathrm{C}$ by circulating water during the tests. The $14 \mathrm{~mm}$ radius rotor with four blades turns in a hollow and fixed external cylinder of $15 \mathrm{~mm}$ of radius. The air gap is $1 \mathrm{~mm}$. The samples are kept at a temperature of $20^{\circ} \mathrm{C}$ by circulating water during the tests. The cement pastes are prepared according to the following protocol:

\subsubsection{Flow test}

The water having a constant temperature of $19 \pm 0.5^{\circ} \mathrm{C}$ and containing the superplasticizer is poured into the mixer. The cement is carefully added to the water and mixed for 1 minute at a low speed, then one minute at high speed. The mixer is stopped for $1 \mathrm{~min} 30 \mathrm{~s}$, during which its walls are cleaned properly with a spatula. The cement blended is mixed for another one minute at high speed. The obtained paste is kept at rest 30s before placing it in the rheometer. The sample is kept at a constant temperature of $20 \pm 1^{\circ} \mathrm{C}$ by an automatic controller during the test.

The composition of the cement paste has been varied, in order to explore the influence of the dosage of the pozzolan on the rheological properties. A pre-shearing of $500 \mathrm{~s}^{-1}$ of all cement pastes during $60 \mathrm{~s}$, followed by a rest period of $60 \mathrm{~s}$ is retained for all the tests. Then the cement pastes are sheared by applying an imposed stress whose interval is (0-200) Pa for 120 s.

\subsubsection{Creep/recovery test}

Each paste was mixed by hand using $50 \mathrm{~g}$ of cement to which is added the appropriate amount of water corresponding to the normal consistency containing the superplasticizer. After $90 \mathrm{~s}$ of mixing, the paste is transferred to the rheometer. A pre-shearing of $500 \mathrm{~s}^{-1}$ is applied for $240 \mathrm{~s}$, followed by a rest time of 60s. The rheological tests therefore begin $6 \mathrm{~min} 30 \mathrm{~s}$ after mixing the cement and the water. This pre-shearing is carried out in order to put the structure of the paste 
in an irreversible state of rupture (Tattersall \& Banfill, 1983). This procedure is performed before each creep measurement.

During the creep measurements, the cement paste is subjected to a constant imposed stress of $0.03 \mathrm{~Pa}$ during $40 \mathrm{~s}$ and a deformation is measured (creep). Then the stress is released and a deformation is measured again for another $40 \mathrm{~s}$ (recovery). Preliminary tests made it possible to determine the imposed stress of $0.03 \mathrm{~Pa}$, belonging to the field of linear viscoelasticity obtained by the stress scan test whose interval is (0.01-20) Pa for a fixed frequency of $1 \mathrm{~Hz}$. The number of identical samples to be tested is three for each mixture.

Concentrated suspensions often have a viscoelastic behavior and creep/recovery measurements can be used to characterize their behavior in flow. A stress is imposed and this, results in a deformation measured as a function of time. Compliance $\mathrm{J}$ can be calculated from these measurements and its variation over time makes it possible to characterize the material as a viscoelastic solid or liquid. Compliance (J) is defined as the deformation divided by the stress. Solids or liquids behave like elastic solids, viscous liquids, viscoelastic solids and viscoelastic liquids under shear stress (Struble and Schultz, 1993).

\subsubsection{Dynamic oscillation test}

The dynamic test is carried out to study the viscoelastic behavior of cement pastes with additions. Knowledge of viscoelastic properties can provide fundamental information about the physical state of a solid particle suspension system transforming to a viscous, semi-solid, fluid system and subsequently to a solid system (Sun et al., 2006). During this test, the shear moduli of storage (elastic) G 'and of loss (viscous) G "of the cement paste can be measured directly by the application of an oscillatory shear stress according to a sinusoidal function and in measuring the corresponding shear deformation During the oscillation test, the controlled stress mode is used, a frequency sweep with a constant stress of $0.03 \mathrm{~Pa}$ is applied.

\section{Results and discussion}

\subsection{Flow test}

The rheological behavior of cement pastes changes with the replacement rate of pozzolan. The flow curves show that the shear stresses to which the cement pastes containing $5 \%$ and $10 \%$ of pozzolan PZ are subjected are weak compared to those of the control paste without the pozzolan (0\% PZ) (Figure 4). The rates of 15\% PZ and 20\% PZ have no positive effect on the flowability of cement pastes since they cause an increase in the shear stress compared to those of the control paste $(0 \% \mathrm{PZ})$. The replacement rate of $10 \% \mathrm{PZ}$ seems to be the optimal rate for a better flow of the paste. This is confirmed by the decrease of viscosity of the cement paste by replacing the cement by the same rate (Figure 5). Furthermore, by modeling the flow curves, the HerschelBulkley model seems to represent well the flow of the cement pastes. The law which describes this model is expressed by equation (1) (Nehdi \& Rahman, 2004):

$$
\tau=\tau_{0}+K \dot{\gamma}^{n}
$$

Where $\mathrm{K}$ is the consistency index or apparent viscosity, $\tau_{0}$ the yield stress which depends on the structural state of the dough, $\gamma$ is the shear rate and $n$ characterizes the behavior of the cement paste. 


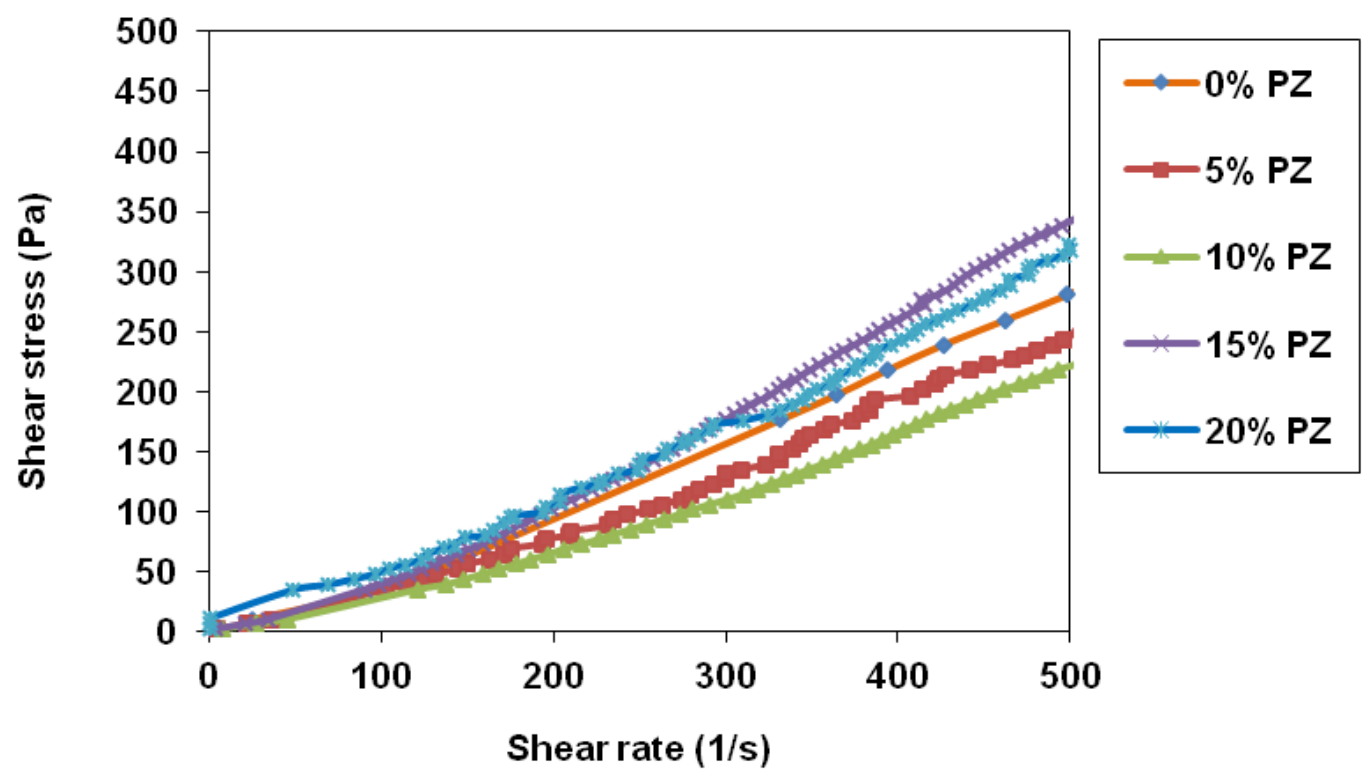

Fig 4. Flow curves of cement pastes containing pozzolan.

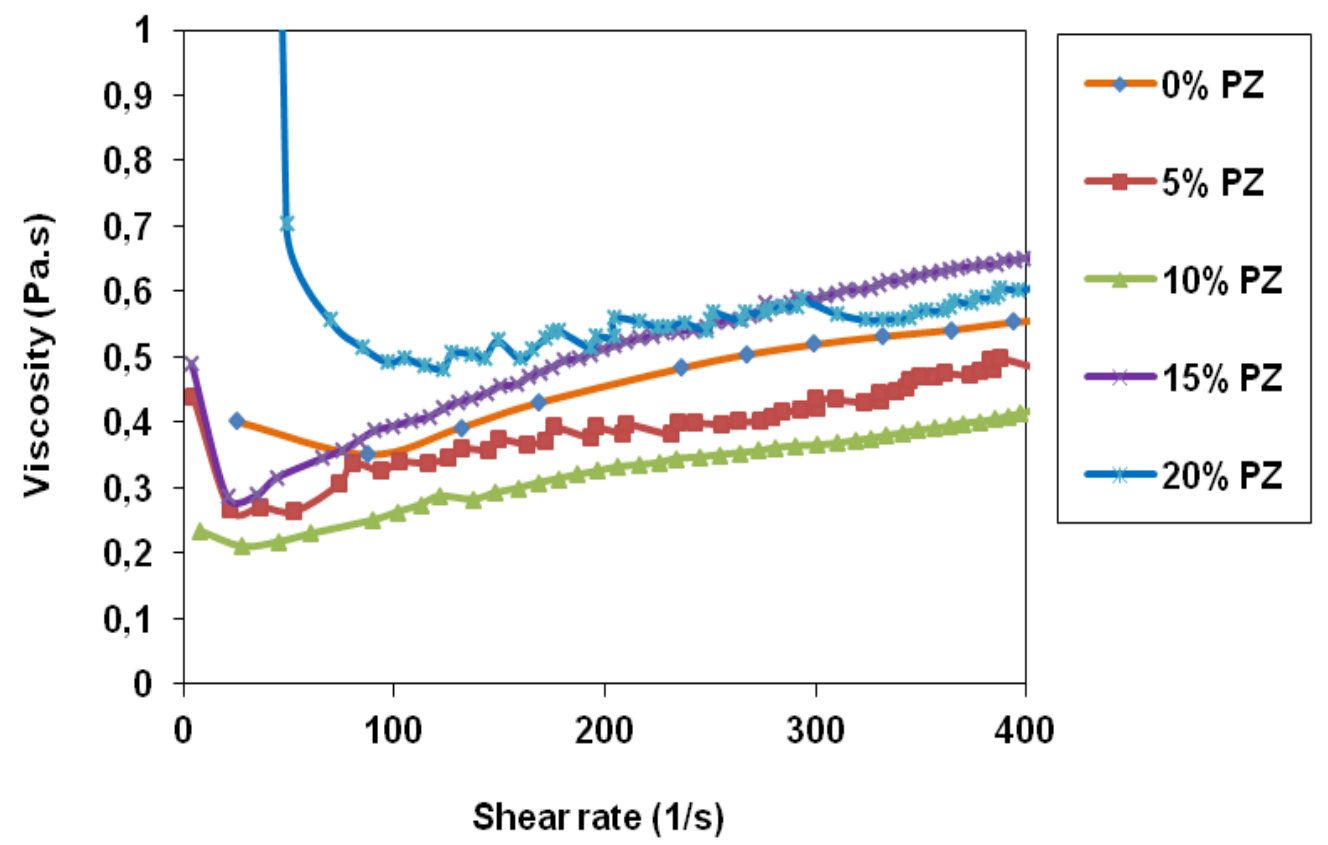

Fig 5. Evolution of the viscosity of cement pastes containing pozzolan.

\subsection{Creep- Recovery Test}

The transient study made it possible to highlight the viscoelastic properties of cement pastes. Those containing pozzolan behave like viscoelastic liquids, even better for the paste containing $10 \% \mathrm{PZ}$ where its behavior is viscous liquid considered to be the best (Figure 6-b). Moreover, the deformations undergone by the latter are the greatest compared to those other cement pastes. The large deformations are characteristic of weak interactions present in the microstructure of the pastes compared to the weak deformations generated in the control paste (Figure 6-a) where the interparticle bonds are strong (Zhang and Han, 2000; Cyr and Legrand, 2000). 


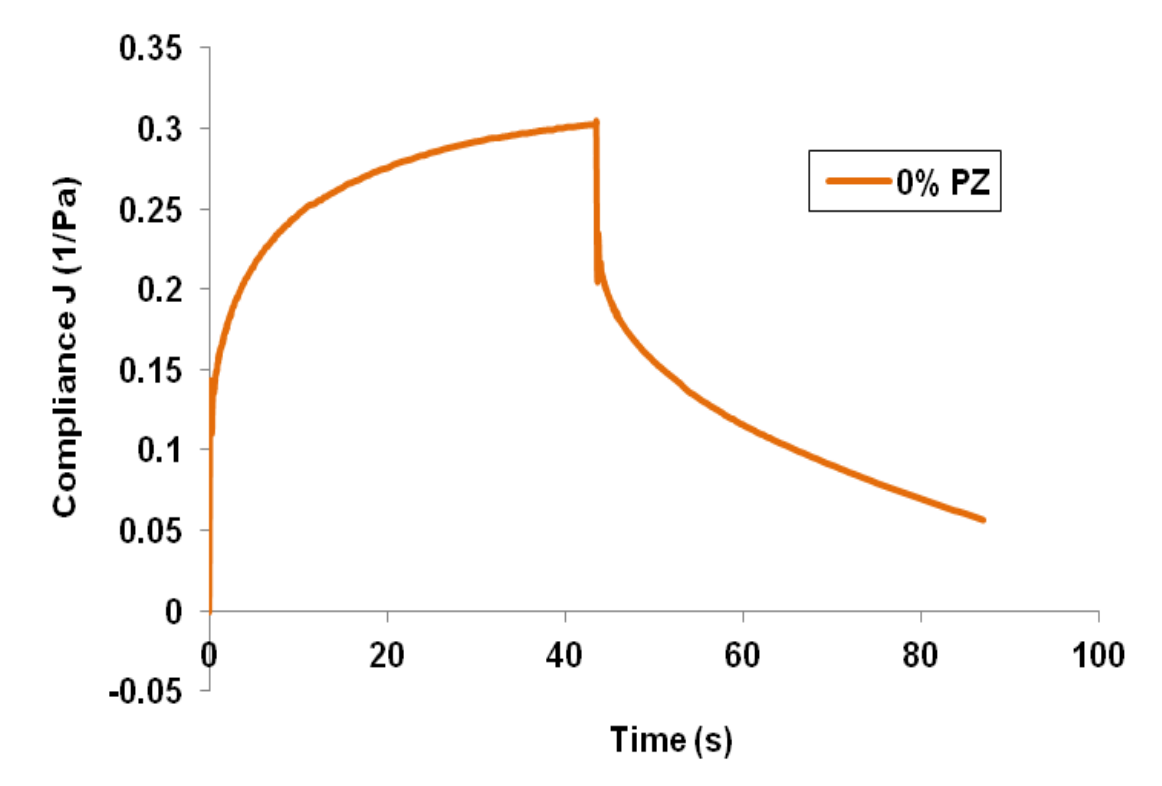

(a)

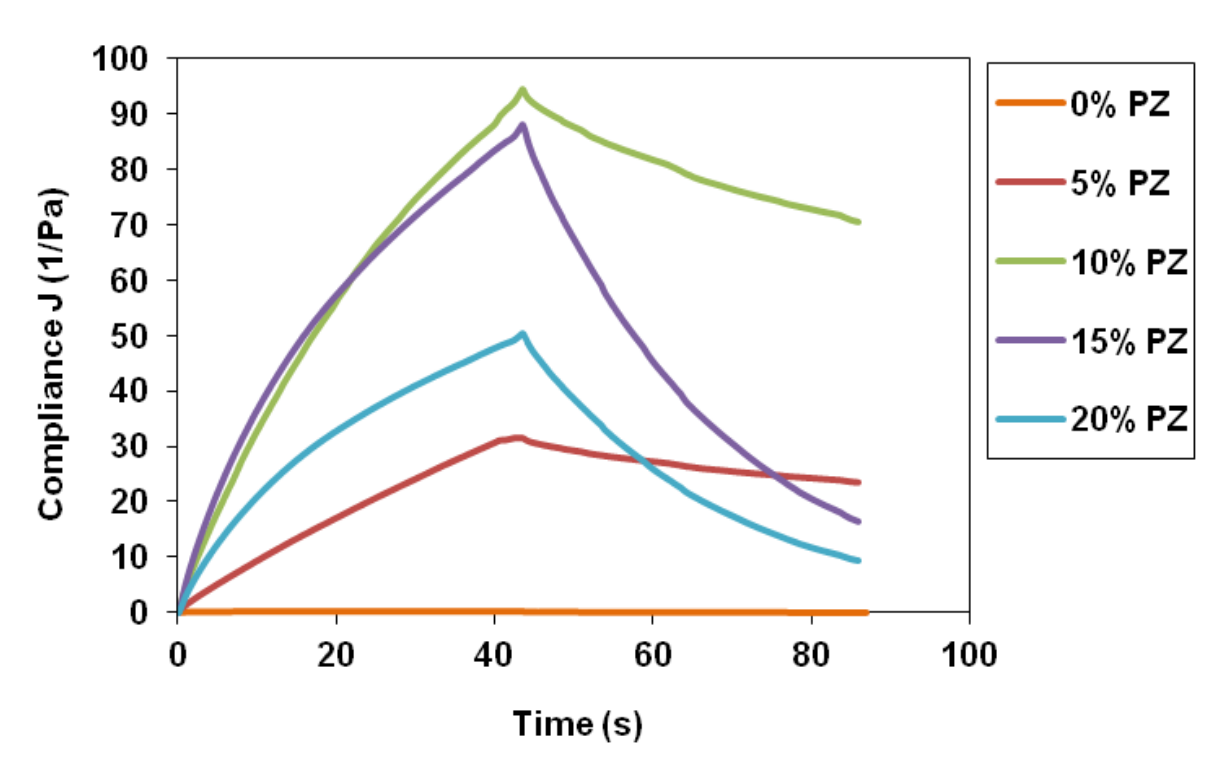

(b)

Fig 6. Creep/Recovery behavior of cement paste (a)- without PZ, (b)-with PZ

\subsection{Dynamic Oscillation Test}

Oscillation tests provided information on the structure of the cement paste thanks to its mechanical properties G" and G' from the first moments after the mixing of the cement paste. Rheometric measurements show a parallel evolution of storage (elastic) modulus $G^{\prime}$ and loss (viscous) modulus G" as a function as frequency (Figure 7). In addition, the shear moduli of cement pastes containing pozzolan are always lower than those of the control paste as shown in Figure 7. In the case of pastes containing pozzolan, the rate of $10 \%$ generates the best behavior. The latter generates a viscous behavior ( $G^{\prime \prime}$ higher than $\left.G^{\prime}\right)$ which allows the flow of the paste at the first moments after mixing, compared to the elastic behavior of control paste (G' higher $G^{\prime \prime}$ ) which characterizes the behavior of a solid. 


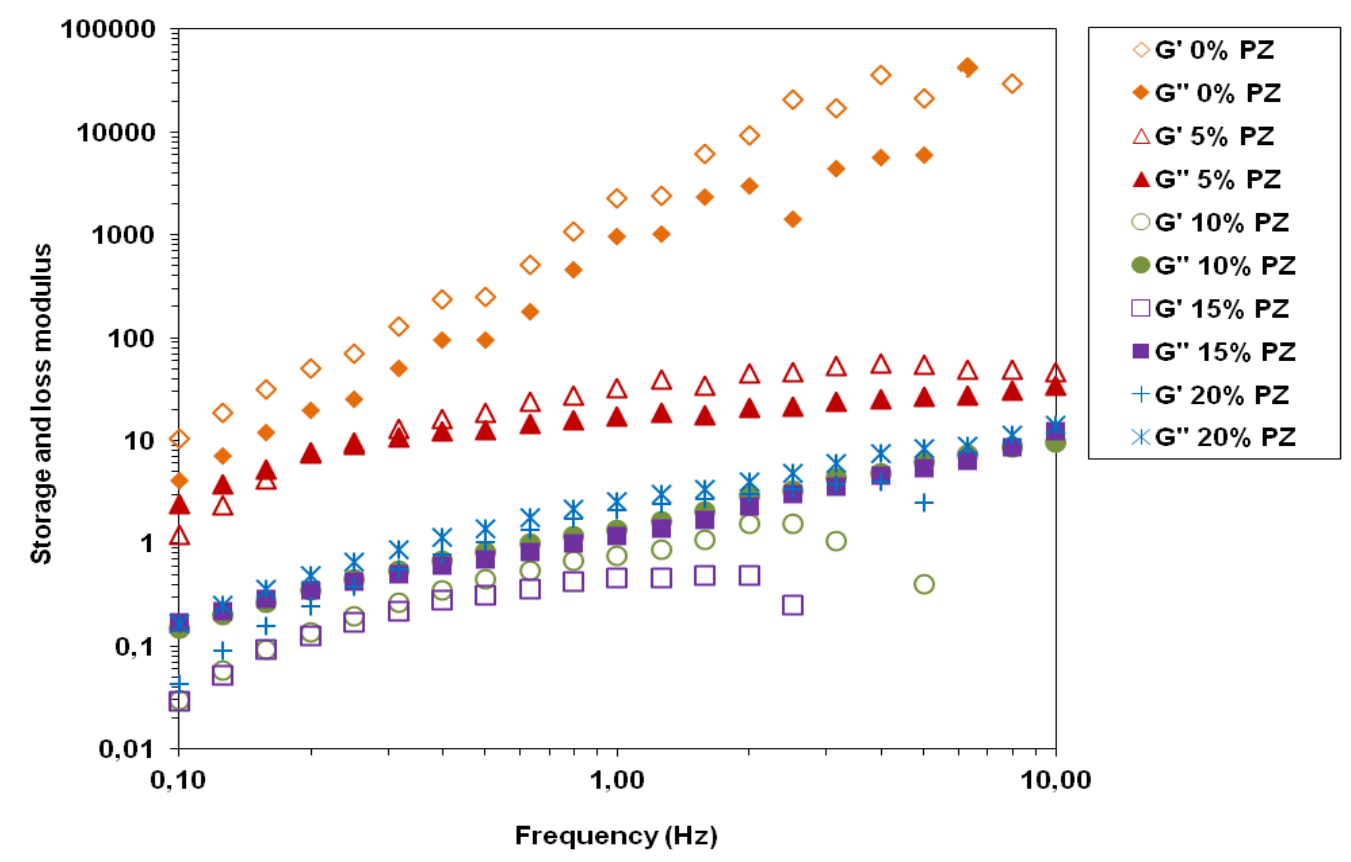

Fig 7. Evolution of storage (elastic) modulus G' and loss (viscous) modulus G" of cement pastes containing pozzolan.

\section{Conclusions}

The major interest which was at the origin of this study is the possibility of replacing part of an industrial material which is the cement by a local and inexpensive mineral addition (pozzolan) in order to reduce the consumption of the cement in Algeria and to improve the rheological behavior of cement pastes in the fresh state which reflects that of the concrete.

The Pozzolan has played its role in improving the fluidity of the flow of cement pastes. It was highlighted the existence of an optimal rate of $10 \% \mathrm{PZ}$ which generated the best fluidity, the best behavior in flow of the pastes and therefore a better flow of the concrete.

The transient study made it possible to highlight the viscoelastic properties of cement pastes. The viscoelastic character decreases with the increase in the replacement rate up to an optimal pozzolan rate of $10 \%$.

In order to better understand the microstructure of cement pastes, a dynamic study has shown that pozzolan generates a viscous behavior of pastes compared to the elastic behavior of control paste.

The results of the dynamic creep and oscillation tests are in agreement with those of the static flow tests, namely that the $10 \%$ replacement rate of pozzolan produces the best rheological behavior.

The rheological study carried out on cementitious pastes has given promising results which further encourage the use of pozzolan as a component of a high performance concrete designated for industry in Algeria, since it will help to improve the workability of concrete in a fresh state and the ease of its installation.

\section{References}

Belaribi, N. B., Semcha, M., \& Laoufi, L. (2003). Influence de la pouzzolane de Beni-saf sur les caractéristiques mécaniques des bétons. Canadian journal of civil engineering, 30(3), 580-584. 
Cyr, M., Legrand, C., \& Mouret, M. (2000). Study of the shear thickening effect of superplasticizers on the rheological behaviour of cement pastes containing or not mineral additives. Cement and Concrete Research, 30(9), 1477-1483.

Ferraris, C. F., Obla, K. H., \& Hill, R. (2001). The influence of mineral admixtures on the rheology of cement paste and concrete. Cement and concrete research, 31(2), 245-255.

Ghrici, M., Kenai, S., \& Said-Mansour, M. (2007). Mechanical properties and durability of mortar and concrete containing natural pozzolana and limestone blended cements. Cement and Concrete Composites, 29(7), 542-549.

Ghrici, M., Kenai, S., Said-Mansour, M., \& Kadri, E. H. (2006). Some engineering properties of concrete containing natural pozzolana and silica fume. Journal of Asian Architecture and Building Engineering, 5(2), 349-354.

Kaid, N., Cyr, M., Julien, S., \& Khelafi, H. (2009). Durability of concrete containing a natural pozzolan as defined by a performance-based approach. Construction and Building Materials, 23(12), 3457-3467.

Khelifa, R., Brunetaud, X., Chabil, H., \& Al-Mukhtar, M. (2008). Consequences mecaniques de l'attaque sulfatique externe sur les betons autoplaçants. Sciences \& Technologie. B, Sciences de l'ingénieur, 23-28.

Lam, T.V., Bulgakov, B.I., Aleksandrova, O.V., \& Larsen, O.A. (2017). Possibility of using ash residues for the production of materials for construction purposes in Vietnam. Bulletin of the Belgorod State Technological University. VG Shukhov, (6). DOI: 10.12737/article_5926a059214ca0.89600468 (In Russian language).

Lam, T.V., Bulgakov, B.I., Aleksandrova, O.V., \& Larsen, O.A., \& Anh, P. N. (2018). Effect of rice husk ash and fly ash on the compressive strength of high performance concrete. In E3S Web of Conferences (Vol. 33, p. 02030). EDP Sciences.

Nehdi, M., \& Rahman, M. A. (2004). Estimating rheological properties of cement pastes using various rheological models for different test geometry, gap and surface friction. Cement and concrete research, 34(11), 1993-2007.

NF EN 196-1(2006). Method of testing cement-part 1: Determination of strength. AFNOR.

NF EN 197-1 (2001). Cement-part 1: Compostion, specification and conformity of cement. AFNOR.

Park, C. K., Noh, M. H., \& Park, T. H. (2005). Rheological properties of cementitious materials containing mineral admixtures. Cement and concrete research, 35(5), 842-849.

Sarker, P., \& McKenzie, L. (2009). Strength and hydration heat of concrete using fly ash as a partial replacement of cement. In Proceedings of the 24th Biennial Conference of the Concrete Institute Australia. Concrete Institute of Australia.

Siad, H. (2010). Influence du type d'addition minérale sur le comportement physico-mécanique et sur la durabilité des bétons autoplaçants (Doctoral dissertation, Rennes, INSA).

Struble, L. J., \& Schultz, M. A. (1993). Using creep and recovery to study flow behavior of fresh cement paste. Cement and concrete research, 23(6), 1369-1379. 
Sun, Z., Voigt, T., \& Shah, S. P. (2006). Rheometric and ultrasonic investigations of viscoelastic properties of fresh Portland cement pastes. Cement and Concrete Research, 36(2), 278287.

Tattersall, G., \& Banfill, P.F.G. (1983). The Rheology of Fresh Concrete, Editions Pitman, Boston.

Zhang, X., \& Han, J. (2000). The effect of ultra-fine admixture on the rheological property of cement paste. Cement and concrete research, 30(5), 827-830. 